\title{
The Uneasy Case For Ecolabelling
}

\section{Peter S. Menell}

\section{Introduction}

Among the most notable social trends relating to the environment during the past decade has been the growing interest among consumers in reducing the environmental consequences of their lifestyle and consumption choices. Strong consumer interest in reducing environmental impacts presents policymakers with an attractive opportunity to address environmental degradation in a way that does not raise regulatory costs. The challenge for public policy lies in providing appropriate information to and educating consumers about how best to integrate environmental concerns into their decision-making.

While the basic idea of informing consumers about environmental effects is straightforward, the task of educating the public is daunting. The environmental impacts of consumer product choices are manifold and complex. Most significantly, consumers have little basis for assessing these impacts when choosing among the myriad products on retail shelves or making other daily choices. Even the most diligent consumer cannot accurately assess the environmental effects caused by the extraction of raw materials, production, and transportation of the product before it reaches the store shelf and any subsequent impacts from usage and ultimate disposal. Comparing these impacts across a range of products within a particular category multiplies the problem. Moreover, many other choices - such as what form of transportation to use, where to live, diet - have important environmental consequences, yet most people would not know where to begin to assess the full range of choices.

Responding to this challenge, the European Community (EC) and Canada have recently developed comprehensive ecolabelling programmes. These programmes employ a newly developed assessment methodology called 'product life cycle assessment' (PLCA). In essence, scientists calculate the total environmental loadings (material requirements, air, water, and land pollution) over the life cycle of different production methods within a particular product category. The EC's programme awards the right to use government-sponsored ecolabels to the top $10 \%$ of products in each category that have the least environmental impact over the life cycle of the product without compromising product or worker safety or significantly affecting the product's performance. ${ }^{1}$

This approach to educating consumers about environmental impacts has been widely praised and promoted by environmentalists and scholars. ${ }^{2}$ To a substantial degree, however, the rush to develop sophisticated comprehensive ecolabelling programmes has proceeded without serious consideration of the overall objectives for government policy or the full range of institutional alternatives. In particular, the role of the price system has been ignored in developing eco-information policy. Yet the price system serves as the principal mechanism for resource allocation within the industrialized world. Price differentials between products serving the same function generally reflect the relative scarcity of the inputs - raw materials, labour, capital, and land - as well as the costs of complying with applicable regulatory requirements, pollution charges, and potential environmental liabilities. Of course, one of the central motivations for eco-information policy is the fact that the market fails to adequately reflect the full environmental costs of consumer choices. If the depletion of raw materials and the effects of pollution are not adequately internalized, then the market system will under-price depletable inputs and polluting products relative to less resource-intensive and cleaner alternatives. This well-recognized distortion, however, has led policymakers and environmental activists to overlook the potential salutary allocative role that the market system can play. The fact that the market may fail to fully reflect environmental impacts does not establish that the price system has no role to play in constructively guiding consumers toward better environmental choices and behaviour. The critical 
question is whether the price system (market-based approach) or ecolabelling provide a better organizing principle for informing consumers about the relative environmental effects of their behaviour.

\section{- An Illustrative Example}

The choice between paper and plastic for products and packaging has been among the most salient ecoinformation issues over the past several years. Environmental activists have sought to replace polystyrene packaging in fast food service with paper packaging. Partly as a result of this fanfare, the choice between paper and polystyrene products on environmental grounds has been thoroughly researched. Consequently, good data is available for comparing the operation of eco-information approaches.

Ecolabelling would unlikely be able to provide consumers with constructive guidance on this choice. The categories of analysis tend to be relatively narrow, such as 'fine paper made from recycled paper' and 'newsprint made from recycled paper', the closest categories from the Canadian Environmental Choice Program. ${ }^{3}$ The closest plastic category considered by the Canadian programme is 'products made from recycled plastics'. The German Blue Angel programme is limited in similar ways. Thus it is unlikely that both polystyrene and waxed paperboard cups would be considered within the same category. The only paperboard category would likely identify manufacturing criteria such as the use of recycled unbleached paper. If the experience in Canada and Germany are indicative of the pressures guiding such a programme, there is unlikely to be any category for polystyrene cups. Hence, the consumer would face the following options at the grocery store: some waxed paperboard cups made of recycled material with an ecolabel, other waxed paperboard cups without a label, and polystyrene cups without ecolabels. The preferred environmental choice within this framework would be waxed paperboard cups displaying an ecolabel. ${ }^{5}$

By contrast, a market-oriented approach would guide consumers to use price, adjusted for downstream costs and quality, as a reflection of total resource costs in the production of a product. Downstream costs would include use costs (such as water and energy consumption) and disposal costs (including solid waste costs) over the life cycle of the product. In the case of disposable cups, the principal comparison would be purchase price, assuming that waxed paperboard and polystyrene cups have comparable quality, reusability, and disposal costs.

To assess the performance of these approaches, we must have an objective basis of actual environmental impacts of the product options. Franklin Associates performed the first comprehensive publicly-available study comparing the environmental impacts of paper and polystyrene cups in $1990 .{ }^{6}$ The Franklin study was sponsored by the Council for Solid Waste Solutions, a plastics industry trade association. This work has been validated by Professor Martin B. Hocking, a chemist at the University of Victoria, British Columbia, who conducted an independent study reaching similar results. ${ }^{?}$

Table 1 summarizes Franklin Associates' estimates of the environmental impacts of paper and polystyrene hot cups. It should be noted that this comparison does not include paperboard cups made from recycled material since this was not a significant product category at the time of the study. The study assumes that no recycling of either final product is being done. A somewhat surprising finding of the study is that polystyrene cups use $31 \%$ less total energy in their manufacturing and product than waxpaperboard cups. Although polystyrene cups consist almost exclusively of petroleum products, the energy savings in their manufacturing and their relatively low material usage per finished product (polystyrene cups consist mostly of air) more than offset the energy consumed in producing paperboard cups.

The direct environmental effects also lead to some surprises. The production of polystyrene cups generates $46 \%$ less atmospheric emissions than the production of paperboard cups. With regard to water pollution, the production of polystyrene cups result in $42 \%$ fewer effluent than the production of paperboard cups. Polystyrene cups produce less solid waste on a weight basis, but take up more landfill space because of their high air content. They have a higher energy content than paperboard cups and hence yield more energy in a waste-to-energy incinerator. Polystyrene

Table 1. Comparison of Environmental Impacts: Disposable Cups (per 10,000 units)

\section{Environmental Impacts}

Energy Consumption (million Btu)

Air Emissions (lbs)

Water Pollution (lbs)

Post-Consumer Solid Waste

lbs

cubic feet

Retail Price (50 cups)
Polystyrene Wax-Coated Paperboard

Sources: Franklin Associates, Inc., Resources and Environmental Profile Analysis of Foam Polystyrene and Bleached Paperboard Containers (June 1990) (prepared for the Council for Solid Waste Solutions) (resource use and environmental impacts); Safeway, Albany, California (April 1992) (price data). 
cups are somewhat safer in a landfill because they are inert and hence do not leach pollutants into the groundwater nor produce methane, both of which can occur with paperboard.

Based upon this analysis, the preferred environmental choice would appear to be the polystyrene cup, unless of course solid waste volume was an overriding consideration or using recycled content would have dramatically altered the environmental impacts of paperboard cups. The price system appears to have reflected at least some of the relevant environmental criteria. The lower price reflected, in part, the lower material requirements, environmental impacts, and superior technology for producing, packaging, and transporting polystyrene cups. In addition, the price approach would allow the consumer to factor in other considerations, such as the superior insulating characteristics of polystyrene. By contrast, an ecolabelling programme would not have provided any basis for choosing between the polystyrene and paperboard alternatives. At best, it might have fostered a market for paperboard cups made of recycled content, although much of the environmental benefits of this product would likely be reflected in the market price.

\section{- Comparative Assessment of Labels and Prices as an Organizing Principle for Eco-Information Policy}

\section{Internalizing Externalities}

The illustration highlights the difficulty of trying to correct for externalities through eco-information policy. Both products use resources and processes that might generate externalities. Even if one were made of recycled material, it would be a great leap to assume that this was a sufficient and accurate proxy for lower environmental externalities. ${ }^{8}$ As is reflected by the life cycle assessments available in numerous product categories, disposable and reusable diapers, orange juice delivery systems, for example, recyclability is one of numerous factors affecting environmental loadings of a product. ${ }^{9}$ More generally, government regulation already internalizes a large proportion of environmental impacts into market prices. In many cases, there are many more 'internalities', circumstances in which the market is reflecting most of the environmental effects, than externalities. Hence an eco-information policy driven by countermanding market signals to reflect environmental effects may lead consumers to disregard what may be the best information feasibly available about relative environmental impacts.
Ecolabelling based upon product life cycle assessment focuses on resource use and effluent flows. Absolute effluent flows, however, are not synonymous with environmental impacts. Such impacts depend critically upon human population density at the location of outflow, the assimilative capacity of the surrounding ecosystem, and the relative effects of different types of effluent (and in different media - air, water, groundwater). Since PLCA is unable to track the site specificity of impacts and lacks a coherent methodology for conducting impact analysis, ecolabels based on such data are poor indicators of actual pollution concerns. Furthermore, the emphasis on narrow product categories, while providing guidance on intra-category choices, provides little advice on inter-category choices. In addition, PLCA can only roughly capture differences in product use and disposal behaviour by different consumers.

By contrast, the price system is sensitive to the effects of pollution (controlling for population densities near outflows and the assimilative capacities of eco-systems) to the extent that regulations and environmental fees appropriately reflect site-specific impacts. Although environmental regulations are far from perfect in this regard, there is significant sensitivity to local factors. Air pollution regulations, for example, are substantially more stringent in regions that have not attained the National Ambient Air Quality Standards. ${ }^{10}$ It is simply more expensive to operate a facility generating effluent in an area with higher pollution control costs, transportation costs, disposal fees, and energy costs. Moreover, with regard to the use of products, consumers directly face locationspecific energy, water, transportation costs, and waste disposal costs. In addition, the price system captures not only direct resource costs in production and distribution, but also the generation of valuable by-products as well as synergies in markets and economies of scale.

Although the regulatory system is far from perfect, the number and size of regulatory gaps have been substantially reduced over the past two decades. Nonetheless, the price system rewards those enterprises that are able to evade environmental requirements. The extent of regulation and environmental enforcement is growing, as well as the extent of externality pricing.

Thus, there is good reason to believe that markets subject to reasonably comprehensive environmental controls may provide better information about relative environmental impacts than ecolabels awarded to narrow sub-classes of products. It may well be true that a recycled waxed paperboard cup receiving a government awarded ecolabel has less environmental impact than other cups in the category of waxed paperboard cups, but such a label does not help us 
in choosing between the waxed paperboard cup and the polystyrene cup. To the extent that product prices reflect a substantial proportion of environmental costs, through either regulatory requirements or environmental charges, the market is more likely to provide a better signal of relative environmental effects than labels based upon narrow sub-classes of products. ${ }^{11}$

\section{Fostering Informed Choice}

While it is unrealistic for government policy to provide consumers with a systematic basis for correcting for environmental externalities, government nonetheless has an important role to play in assisting consumers in navigating the complex range of choices that they confront in daily life. The efficacy of different eco-information approaches can be evaluated according to their comprehensibility, universality, and ability to enable consumers to prioritize among environmental choices.

\section{Comprehensibility}

Ecolabelling is reasonably comprehensible because of its clear environmental stamp of approval within a product category. In effect, ecolabelling dictates choices to environmentally conscious consumers. The main problem is knowing how broad a group of functionally similar products are included within the same category. Because of the limited space on a label for delineating categories and lay consumers' inability to judge omitted information, the comprehensibility of ecolabelling is often illusory in practice.

Ecolabelling may mislead consumers not by directly misinforming consumers but through implicit inferences that consumers are likely to draw. In the disposable cup example, an ecolabel only on cups made of recycled content leads consumers to make the inference that other options, such as polystyrene cups, do not measure up on environmental grounds. Since other products and packaging will often not have even been evaluated, this inference is misleading. This circumstance occurs commonly in the Canadian Environmental Choice Program. Categories exist for reusable cloth diapers and diaper services, but not disposable diapers; ethanol-blended gasoline, but not other gasolines or other fuels (e.g., compressed natural gas); non-rechargeable batteries, but not rechargeable batteries. ${ }^{12}$ Germany's Blue Angel programme does not label roll-on deodorants, but does label aerosol sprays. Even if an ecolabelling programme provided labels for paperboard and polystyrene cup categories, there would still be no basis for comparing across these categories.

By contrast, the price system avoids making a direct claim that it reflects only environmental considerations, yet it provides reasonably good information on resource costs. Through their direct involvement in the market process as workers, consumers, and investors, most people recognize that the market reflects many factors. A government information policy emphasizing the importance of environmental effects among these many factors would not likely lead consumers to think that price is synonymous with environmental impacts, but rather a good statistic for gauging such impacts in an extremely complex economy.

The price system is reasonably straightforward to apply with regard to most consumer decisions. Consumers in a market economy are accustomed to the price system. Comparative shopping is a skill learned early in life and reinforced throughout a person's life, whether in making personal choices or working for others. Most advertising, consumer guides, and other readily accessible materials provide information relevant for comparative shopping. In fact, the unit pricing provided in most grocery stores is specifically designed to aid consumers in using the price system.

The principal area where consumers encounter difficulty in using the price system involves products and activities for which costs occur over time. Automobiles and major appliances have up-front costs as well as significant costs over time: in the case of automobiles, maintenance, gasoline, insurance and energy; in the case of washing machines, water use and energy. Consumers might also have difficulty incorporating costs of ultimate disposal, which may occur weeks or years after purchase, into their purchasing decisions.

\section{Universality}

By focusing on narrow product categories in order to conform to the limitations of product life cycle analysis, ecolabelling provides reasonably accurate environmental information only within narrow product categories. Where an ecolabel has been awarded to one product (e.g., a recycled paperboard cup), the consumer cannot readily assess how that product compares to functionally similar but compositionally different substitutes (polystyrene). Consumers cannot readily detect omissions in the information that they receive, leading them to infer that the labelled product is environmentally superior. As the disposable cup example highlights, this cognitive bias can be misleading in assessing products across ecolabelling, but not necessarily functional, categories.

More generally, ecolabelling omits many product and packaging categories, as well as consumer behaviour not directly based on purchasing, such as the use of appliances and the disposal of wastes. A study of the environmental impacts of washing machines, for example, found that most of the variation in life cycle environmental effects was attributable to how the 
machines were used and not how they were made. ${ }^{13}$ Yet ecolabelling alone cannot capture these aspects of environmental behaviour.

The universality of the price signal as a reflection of resource costs provides consumers with a powerful tool for understanding a broad array of consumer choices. Pricing exists through a broad variety of means beyond merely the cash register at a store. For example, the use of an air conditioner is charged through monthly electric bills; littering risks the imposition of a substantial fine (and social and moral stigma); solid waste through curbside fees.

The price system enables consumers to assess not only the full range of choices for cups, but also the choice between a vegetarian and a meat-centred diet. Because meat production requires many pounds of vegetable protein for each pound of meat protein and substantially more additional growing and processing resources, the price system favours a vegetarian diet on a resource basis, so long as the consumer does not purchase vegetables that are particularly costly to grow or must be imported over large distances. Similarly, a trek in the Himalayas, while environmentally inspiring, requires substantially higher transportation costs (and likely higher environmental impacts) than a trek closer to home. By emphasizing the implicit resource trade-offs in all consumer decisions, a market-oriented eco-information policy provides a much more pervasive appreciation of the relationship between human behaviour and the environment.

\section{Establishing Priorities}

As an ordinal index - merely conveying that products receiving a government-sponsored label are preferable to those in the same category not receiving such a label - ecolabels provide no indication of the relative environmental importance of consumer choices. It is possible that consumers will attach significance to the fact that certain categories are evaluated for labels, inferring that there are particularly important environmental opportunities in those product areas. In view of the arbitrary process by which product categories are selected for evaluation, and the potential bias against other categories (e.g., exclusion of products made of plastic), this relative signal is likely to be misleading.

By contrast, the price system provides a clear system of prioritization. In choosing among disposable cups, the consumer faces a cardinal metric - product prices (adjusted for downstream costs such as waste disposal costs where applicable). The relative ranking of choices is reflected in a monetary index which integrates all of the resource costs which are internalized. The consumer can plainly see whether the price differential is a few percent or three hundred percent.
With regard to the choice between polystyrene and paperboard cups, a red flag would go up. Unless there are enormous labour cost differences and/or immense environmental externalities attributable only to polystyrene cups, the price system is signalling that polystyrene cups are consuming fewer resources and/or causing less pollution.

\section{Further Limitations of Ecolabelling}

Moving beyond the disposable cups example, ecolabelling programmes have other significant limitations as the organizing principle for eco-information policy. Ecolabelling programmes base their message to consumers on the results of product life cycle assessments of consumer products, a methodology with severe limitations. ${ }^{14}$ Standard methodology, for example, assumes that production processes meet all applicable environmental standards and guidelines. Since the major environmental concerns relate to loadings above the assimilative capacity of the receiving ecosystem, such an assumption largely ignores the problem to be addressed. Moreover, even if it was realistic to track site specific impacts, there is no accepted methodology for translating resource requirements and environmental loadings into a coherent measure of human and ecosystem impacts. Thus we are typically left comparing absolute loadings across different products and production methods. Unlike the disposable cup example, where all of the loadings (except volume of solid waste) favoured one option (polystyrene), we often encounter more ambiguous results. For example, disposable diapers use more input materials and generate greater solid waste than cloth diapers, whereas cloth uses more water and result in greater water pollution. Without a methodology for assessing impacts across media, PLCA is incapable of providing clear answers to many of the choices consumers face.

The experience of those nations that have pursued ecolabelling programmes suggests that ecolabelling, even if based on state-of-the-art product life cycle assessment, is prone to severe distortion as a result of the political economy of environmental policy. Although the formulation of ecolabelling programmes appears to be neutral, the implementation has been heavily influenced by perceptions of what is environmentally sound. As discussed earlier, the Canadian and EC programmes exclude products and packaging made of plastics, with limited exceptions for products made of recycled plastics, despite numerous studies showing environmental advantages to the use of plastics. ${ }^{15}$ A recent article about ecolabelling programmes notes that:

[s]chemes are likely to concentrate on products whose use environmentalists want to promote (biodegradable engine oil in Canada, building materials made from waste paper in Germany). The testers will tend to neglect more 
common items, whose effect on the environment may worry shoppers but be difficult to measure or simply bore environmentalists. ${ }^{16}$

The methodology of ecolabelling programmes invites political influence in implementation. Product life cycle analysis was developed in part to provide a more systematic basis for evaluation. Because of cost and data limitations, however, PLCA requires numerous simplifying assumptions which makes the analysis prone to manipulation in practice. Where the stakes are significant, the use of PLCA inevitably results in a battle of the experts, with different industries using well-financed consultants to favour particular outcomes or question unfavourable policy outcomes. Bureaucrats will either have to confront highly politicized labelling decisions or avoid considering categories likely to engender controversy. Although the use of independent review panels is designed to reduce these problems, it is unlikely that manufacturers who have much to gain or lose from labelling standards will refrain from lobbying government officials at any and all levels of potential influence.

Ecolabelling programmes also invite trade protectionism in the guise of environmental protection. ${ }^{17} \mathrm{Germ}$ any's ecolabelling systems and packaging return regulations have been attacked as discouraging foreign competition in product markets and recycling. ${ }^{18} \mathrm{Com}$ plaints of trade protectionism have already been raised with regard to the EC's nascent ecolabelling programme. ${ }^{19}$ Brazilian businesses have complained that foreign manufacturers have been excluded from working groups developing category definitions and product standards. They are also concerned that labelling standards will favour domestic resources. The fact that environmental labelling programmes might discourage imports does not mean that they would not produce environmental benefits or that such benefits do not justify a reduction in trade. Rather, it points to the potential for ecolabelling programmes to serve as instruments in protectionist battles. They create perverse incentives for domestic industries to influence programmes less for environmental objectives than protectionist gains.

\section{Additional Advantages of a Market- Oriented Approach}

Unlike ecolabels, which limit consumers' choice to buying or not buying a particular labelled product, the price system affords consumers much wider latitude to prioritize and channel their investments to improve the environment. For example, even if waxcoated paperboard cups had lower material usage and environmental loadings (contrary to Table 1) but remained two to three times more costly than polystyrene cups, the environment might be better served if consumers purchased polystyrene cups and Blackwell Publishers Litd. 1995. donated the price differential to preserve valuable ecosystems. For example, for every 93 cents spent on disposable cups, consumers could donate US $\$ 1.92$ to the Nature Conservancy. Rarely will the return to the environment of consumers' favouring a particular product be of this magnitude. Ecolabelling in effect bundles the consumer's product choice and his or her environmental investment. The fungibility offered by the price system enables a decoupling of consumption and environmental investments, which may more effectively protect the environment.

In addition to its direct allocative function, the price system can serve as a valuable eco-educational device. Consumers are familiar with the operation of markets as general allocational mechanisms through comparison shopping and hence can be readily taught about its relevance to environmental criteria. With some supplemental information, such as the energy and water costs involved in the use stage of appliances and the disposal costs of various waste materials, consumers can readily develop an ability to perform rough life cycle costing of products. Over time, this process would become intuitive to most consumers in much the way that other comparative shopping techniques have become inculcated. In this way, the price system can serve as a dynamic learning device, bringing consumers satisfaction in terms of money saved and the knowledge that they are reducing their impacts on the environment.

A market-oriented approach would complement other elements of eco-information policy such as energy efficiency labelling. A market-oriented approach also comports with the emerging direction of environmental policy toward market-based instruments. ${ }^{20}$

\section{Conclusions}

In the real world of complex and costly information, imperfect institutions, and cognitive limitations, it is unrealistic to expect government policy to inform consumers perfectly about the environmental consequences of their product and lifestyle choices. The goal of public policy must be to design the best system in view of these limitations and constraints.

The principal approach to eco-information policy throughout the industrialized world has been the use of point-of-purchase labels to guide consumers to 'preferred' environmental choices. Ecolabelling programmes are increasingly seen as a comprehensive solution to the problem of confusing green marketing claims and a powerful incentive device to reduce environmental impacts. The efficacy of this approach is highly questionable, however, especially by comparison to intelligent use of the price system. Ecolab- 
elling provides consumers with a detailed (and imperfect) view of but a few trees, but obscures the larger forest of options. It reinforces a highly limited understanding of the opportunities for consumers to lessen environmental impacts and perpetuates common misperceptions about the environmental impacts of consumer choices. By contrast, the price system offers consumers a simple, flexible, and readily available guide to the broad range of choices. While imperfect, it provides the better organizing principle for structuring eco-information policy. Rather than supplant the price system with a limited, costly, imprecise, and potentially manipulable alternative, eco-information policy should be integrated directly into the price system and the environmental regulatory regime.

This is not to suggest that ecolabels have no role in informing consumers or reducing environmental degradation. Ecolabels can be effective in encouraging manufacturers to improve environmental performance of products within product categories. Nonetheless, such an effort must not undercut the important role of the market in providing the key guidepost to consumers in developing a framework for integrating environmental concerns into their product and lifestyle choices. Government policy should affirmatively emphasize the central role that the market plays in revealing resource and environmental costs and educate consumers about how to use the price system effectively to make sound environmental choices.

\section{Notes}

1. Council Regulation 880/92/EEC, OJ L99, 11.4.92 at 1; Matt Haddon, 'Making Green Labels Stick', New Scientist, 20 June 1992, 23-24.

2. Suzanne Clabon, 'Ecolabelling', RECIEL, 3:1 (1994) 21, at 21; James A. Grodsky, 'Certified Green: The Law and Future of Environmental Labelling', Yale J Reg, 10:1 (1993), 147; Denis Hayes, 'Harnessing Market Forces to Protect the Earth', Issues in Science \& Technology, Winter 1990-91, 46.

3. Environment Canada, In the Market for a Better World (Ottawa, Queen's Printer, 21 January 1993). The Environmental Choice Program has issued draft guidelines for 'Unbleached Paper Products,' and 'Bleached Paper Products'. Id.

4. Id.

5. According to environmental buying guides, the preferred choice between paper and polystyrene cups is neither. See U.S. Environmental Protection Agency, The Environmental Consumer's Handbook (Washington, D.C., US EPA, 1990), 11. These guides urge consumers to prefer ceramic mugs or other reusable containers. Even this conventional wisdom, however, may be based more on perceptions than actual environmental effects. A recent study conducted by the Dutch Ministry of the Environ- ment comparing the life cycle costs of using a china coffee cup and saucer with disposable alternatives highlights the complexity of the choice between reusable and disposable cups. See 'Washed Up', The Economist, 1 August 1992, at 58. Moreover, the option of reusable cups is not always available.

6. Franklin Associates, Inc., Resources and Environmental Profile Analysis of Foam Polystyrene and Bleached Paperboard Containers (June 1990).

7. Martln B. Hocking, 'Policy Forum Paper Versus Polystyrene: A Complex Choice', Science, 251 (1991), 504. Numerous letters criticizing Hocking's assumptions and his rejoinder are published in Science, 252 (1991), 1361.

8. Chris Hendrickson, Lester Lave and Francis McMichael, 'Time to Dump Recycling?', Issues in Science and Technology, Spring 1995, at 79.

9. Peter S. Menell, 'Eco-Information Policy: A Comparative Institutional Approach', (John M. Olin Program in Law and Economics, Stanford Law School, Working Paper No. 104, April 1993).

10. Peter S. Menell and Richard B. Stewart, Environmental Law and Policy (Boston, Little, Brown \& Co., 1994), 345-73.

11. This is not to say that product prices perfectly reflect all or only environmental costs. Product prices are a composite of material, labour, capital, regulatory, and other costs. Thus the consumer will not be able to separate out the environmental component. Such information, even if separable, however, would not be particularly useful given the substitutability of inputs. For example, product A might have higher labour costs because the manufacturing process relies upon workers sorting through input material in order to reduce emissions while competing product B might invest more in equipment to capture the emissions and safely dispose them. A full accounting of costs would indicate that product $A$ has lower environmental costs but higher labour costs, yet the environmental impacts might be the same so long as both manufacturers are adhering to all applicable environmental regulations. In view of the high degree of environmental cost internalization, eco-labels will not be able to systematically correct for environmental externalities. More likely, they run the risk of undermining the regulated market's ability to reflect the many environmental 'internalities'. The worthy goal of trying to provide consumers with sufficient information to correct for environmental externalities is unrealistic in practice.

12. Environment Canada, n.3 above.

13. 'Eco-babble', The.Economist, 21 September 1991, at 85.

14. Peter S. Menell, n.9 above, at 30-39; Paul Portney, 'The Price is Right: Making Use of Life Cycle Analyses', Issues in Science \& Technology, Winter 1993-94, at 69.

15. William Rathje and Cullen Murphy, Rubbish! The Archaeology of Garbage (New York, Harper Collins Publishers, 1992), 216-220 (reporting study of US and Mexican waste disposal showing that skilful packaging of food products significantly reduces wastage of foods; 'Environmentalism Too Strong to Suffer Setbacks of the 1970s', Envtl Compliance Update, 199:2 (1992) (describing a 1988 German study finding that a ban on plastic packaging would quadruple the weight of packaging, double packaging volume, double energy consumption, and double the cost to consumers). 
16. n.13 above, at 85 .

17. See generally: 'Trade and the Environment: The Greening of Protectionism', The Economist, 27 February 1993, at 25; Richard B. Stewart, 'International Trade and the Environment: Lessons from the Federal Experience', Wash \& Lee L Rev, 49 (1992), 1329 at 1333-35; Marc Levinson, 'The Green Gang's', Newsweek, 3 August 1992, at 58.

18. 'European Regulation Update: Eco-Labelling, Eco-Auditing, Eco-Packaging', Green Market Alert, 1:1 (1993); Joachim Schypek, 'Germany on Trial Over Green Packaging: Green Light for German Packaging', Marketing, 2 July 1992, at 14.

19. 'EC Eco-Label Program Raises Concerns for Brazilian Business, Government Officials', BNA Int'l Env't Reptr, 27 January 1993, at 43-44; Amanda Marcus and John Peter- son, 'Is the Future Written in the Stars; Environmental Labelling of Paper Products,'Paper and Pulp International, 33:11 (1991), 96.

20. Peter S. Menell and Richard B. Stewart, n.10 above; Robert W. Hahn and Robert N. Stavins, 'Incentive-Based Environmental Regulation: A New Era from an Old Idea?', Ecol L Q, 18:1 (1991), 1 .

Peter S. Menell is Professor of Law at the University of California at Berkeley School of Law. A longer version of this article is published in Roger van den Bergh and Erling Eide (eds.), Law and Economics of the Environment (1995). 